\title{
Impactos de políticas de avaliação institucional: um estudo de caso no sistema de ensino naval brasileiro
}

\author{
Natália Morais C. B. de Aguiar \\ Ana Canen
}

\section{Resumo}

$\bigcirc$ presente artigo trata de um estudo de caso referente à avaliação institucional no Sistema de Ensino Naval, a partir de uma perspectiva multicultural que busca trabalhar as tensões inerentes ao processo avaliativo, levando em conta a missão institucional da Marinha, sua especificidade identitária e cultural, as influências híbridas entre discursos do SINAES e os da qualidade total em educação e a necessidade de reconhecer a diversidade cultural nela própria inerente, como organização multicultural. Concluímos, sugerindo que o olhar multicultural pode ajudar na compreensão de possíveis caminhos pelos quais a avaliação institucional possa avançar no processo de crescimento de instituições e atores educacionais.

Palavras-chave: Avaliação institucional. Sistema de Ensino Naval Brasileiro. SINAES. Multiculturalismo. Marinha do Brasil.
Abstract

Impacts of policies of institutional evaluation: a case study in the brazilian naval system

The present article analyses a case study of institutional evaluation in the Brazilian naval education system, from a

\section{multicultural}

perspective that seeks to address the tensions inherent to evaluative processes. It takes into account the institutional mission of the naval education system, its singular cultural identity, as well as the hybrid influences of the SINAES discourses and those of total quality in education, besides the need to recognise cultural diversity within its own space as a multicultural organisation. We conclude by suggesting that multiculturalism can help in the understanding of possible ways by which institutional evaluation may help institutions and their actors grow. 
Keywords: Institutional evaluation. Brazilian Naval Education System. SINAES (National System of Evaluation of Higher Education). Multiculturalism. Brazilian Navy.

\section{Resumen \\ Impactos de políticas de evaluación institucional: un estudio de caso en el sistema de enseñanza naval brasileño.}

El presente artículo trata de un estudio de caso referente a la evaluación institucional en el Sistema de Enseñanza Naval, a partir de una perspectiva multicultural que busca analizar las tensiones inherentes al proceso evaluativo. Considera la misión institucional de la Marina, su identidad específica y cultural, las influenzas híbridas entre los discursos del SINAES y aquellos de la calidad total en educación, bien como, la necesidad de reconocer la diversidad cultural característica de una organización multicultural. Concluyendo, se sugiere que la visión multicultural pode ayudar en la comprensión de los caminos posibles para el avanzo del proceso de crecimiento de las instituciones y actores educacionales.

Palabras claves: Evaluación institucional. Sistema de Enseñanza Naval Brasileño. SINAES. Multiculturalismo. Marina del Brasil.

\section{Introdução}

Atravessamos o milênio com tensões entre paradigmas educacionais que têm sido percebidos como ora enfatizando critérios de qualidade total e voltados ao vocabulário do mercado e outros que preconizam responsabilidade social, valorização da diversidade cultural e valores associados à cidadania e ao fomento da consciência crítica. Entretanto, em uma perspectiva multicultural que abraçamos, tais dicotomizações deixam de considerar hibridizações, tensões, movimentos e construções discursivas pelos quais políticas e paradigmas se traduzem no cotidiano das instituições de ensino, particularmente no campo da avaliação institucional.

Nesse sentido, trata-se, no caso da avaliação, de trabalhar com as tensões inerentes ao processo avaliativo, entre o objetivismo e o subjetivismo, entre a regulação da qualidade - esta, longe de ser um construto universal - e a valorização da diversidade cultural das identidades institucionais, na construção de um equilíbrio sempre contingente e móvel no complexo processo avaliativo (CANEN, 2005).

A partir desse olhar, o presente artigo bus$c a$, em um primeiro momento, discutir perspectivas de avaliação institucional, identificando as tensões acima referidas, bem como salientando o viés ideológico que permeia a avaliação enquanto conceito e em políticas e discursos que a ela se referem. A segunda parte trata de um estudo de caso referente à avaliação institucional no Sistema de Ensino Naval - SEN, emblemático das tensões da avaliação que apontamos, transitando entre dimensões avaliativas que devem proceder ao controle de qualidade levando em conta a missão institucional da Marinha, sua especificidade identitária e cultural e a necessidade de reconhecer a diversidade cultural nela própria inerente, como organização multicultural (CANEN, A.; CANEN, A. G., 2005; CANEN, A. G.; CANEN, A. 2005), com conseqüências na hibridização de discursos ava- 
liativos aí presentes. Concluímos, sugerindo que o olhar multicultural sobre as tensões avaliativas pode ajudar na compreensão de possíveis caminhos pelos quais a avaliação institucional possa avançar, cada vez mais, como processo de crescimento de instituições e atores educacionais.

\section{Avaliação institucional e políticas no Brasil: um olhar multicultural}

multiculturalismo tem sido tratado particularmente em termos de identidades individuais e sua representação em currículos e políticas educacionais. Entretanto, temos argumentado que o olhar multicultural pode ser interessante como perspectiva de análise, a partir da consideração de sua categoria central - identidade - para o âmbito das instituições. Canen e Canen (CANEN, A.; CANEN, A. G., 2005; CANEN, A. G.; CANEN, A. 2005), por exemplo, referem-se às identidades institucionais e às organizações multiculturais, onde tensões entre a valorização da diversidade e a necessidade de construção de uma identidade institucional, a partir de sua missão e projeto, são objetos de análise, nessa perspectiva.

A avaliação institucional, no bojo dessas tensões, é particularmente importante no olhar multicultural. Tratando de um juízo de valor, a partir de critérios, para a tomada de decisões, a avaliação depara-se com discussões paradigmáticas entre os que defendem critérios claros, aprioristicamente tratados para a avaliação e os que argumentam pela negociação de tais critérios, localmente definidos a partir dos diálogos com os sujeitos envolvidos. As tensões que se apresentam permeiam, a partir do multiculturalismo, as próprias identidades institucionais de organizações multiculturais: de um lado, avaliá-las a partir de suas identidades específicas, locais, com respeito às mesmas $e$, portanto, partindo de critérios relativizados ou, ao contrário, avaliá-las a partir de perspectivas que, em uma visão mais "universalista", de controle e regulação, definiria, a priori, o que seja uma instituição de qualidade?

Tal dicotomização passa pelas próprias tensões entre visões universalistas e particularistas ou relativistas, nos vários campos do saber e tem permeado as discussões sobre avaliação, inclusive na descrição das chamadas "gerações de avaliação" (GUBA; LINCOLN, 2003; PENNA FIRME, 1994). De fato, enquanto se verifica a ênfase em critérios apriorísticos, voltados à mensuração, à descrição e ao julgamento de valor, nas três primeiras gerações, uma guinada para o outro pólo da dicotomia ocorre no caso da quarta geração, em que se parte para a defesa da negociação dos critérios avaliativos, relativizados no contexto plural dos sujeitos avaliados em um horizonte de consenso e de construção de critérios em parceria com os envolvidos.

Argumentamos que articular paradigmas e superar dogmatismos e dicotomizações, no que tange às identidades individuais, também podem ser pensados na visão mais abrangente do multiculturalismo sobre as identidades institucionais e as organizações multiculturais. No caso da avaliação institucional, trata-se de visualizar o equilíbrio dinâmico entre o pólo da regulação - entendendo seu caráter contingente, de construção de critérios que não são universais, mas são construídos em função de projetos de governo, de nação - e o pólo da diversidade cultural, da negociação, da ressignificação dos critérios em um sentido 
de "globalização" - o global ressignificado no local, no contingente. A partir de tal olhar, temos argumentado pela superação das dicotomias do tipo avaliação objetivista e avaliação responsiva, regulação e relativismo, avaliação por processo, formativa e diagnóstica e avaliação por produto, somativa e classificatória. Nesse sentido, o desafio do avaliador será trabalhar as tensões da avaliação, buscando perceber a complexa relação entre respeito à identidade institucional e regulação da qualidade de ensino, tendo em vista projetos educacionais mais amplos, bem como as fertilizações possíveis entre processos avaliativos de caráter regulador, somativo e aqueles formativos, diagnósticos.

Tal olhar tem permitido argumentarmos que - Sistema Nacional de Avaliação da Educação Superior - SINAES, instituído pela Lei $\mathrm{n}^{\circ}$ 10.861 de 14 de abril de 2004 (BRASIL, 2004), assentado no tripé avaliação das instituições de ensino superior, dos cursos de graduação e do desempenho acadêmico dos estudantes - tem avançado, com relação a políticas anteriores, na direção da articulação da tensão entre a regulação e o respeito à diversidade, no âmbito da avaliação. Ao assentar-se em princípios norteadores que incluem a responsabilidade social com a qualidade da educação superior; o reconhecimento da diversidade do sistema; o respeito à identidade, à missão e à história das instituições; a globalidade institucional, a utilização de um conjunto significativo de indicadores, considerados em sua relação orgânica; e a continuidade do processo avaliativo como instrumento de política educacional para cada instituição e o sistema de educação superior em conjunto, O SINAES (INEP, 2004) busca trabalhar as tensões acima citadas. Dias Sobrinho (2004) refere-se ao sentido político, social e ético que impregnam a avaliação aí concebida, voltada, como sugere, à exigência de melhorar e aumentar a qualidade do serviço educacional, promover a eficácia institucional e elevar a efetividade acadêmica e social, tendo como referência as necessidades da população.

Neste enfoque, reforça-se a idéia de criar uma cultura de avaliação, conforme já proposto por Ristoff (1996), onde a comunidade educativa assume coletivamente as responsabilidades na construção da qualidade científica e social da Instituição de Ensino Superior. Assim, defendemos que, quando a avaliação é verdadeiramente um processo de construção coletiva, a negociação e a emancipação podem fazer parte desse processo de busca de melhoria com vistas a alcançar objetivos comuns a toda comunidade escolar, valorizando a qualidade política; entretanto, a articulação dessa construção com uma visão mais ampla de formação e um projeto de cunho nacional pode, argumentamos, ser possível, a partir do olhar sobre as tensões entre os pólos trabalhados de regulação e valorização da diversidade e das identidades institucionais e o equilíbrio estabelecido entre os mesmos.

A seguir, ilustraremos nosso argumento a partir da análise da avaliação institucional no Sistema de Ensino Naval, tomado como estudo de caso, emblemático das tensões da avaliação ora em tela.

\section{Sistema de Ensino Naval: um estudo de caso da avaliação institucional: contexto e intenções}

A avaliação do Sistema de Ensino Naval tem dois momentos nesses últimos dez anos. 
A primeira metodologia foi implantada na Marinha, em caráter experimental, em 1996. Ela teve como objetivo elaborar e validar uma proposta de sistemática de avaliação contínua destinada ao Curso de Formação de Marinheiros, ministrado nas Escolas de Aprendizes-Marinheiros. Até então, cada Organização de Ensino da Marinha avaliava seus cursos de maneira independente, com instrumentos e critérios diferenciados. Esta metodologia foi posteriormente adaptada a outras modalidades de cursos, para que todas as Organizações de Ensino da Marinha utilizassem um modelo de avaliação único, que englobasse todo o SEN. No período de 1996 a 2004, a metodologia foi sofrendo pequenas mudanças e os ajustes eram feitos conforme sugestões das Organizações Militares (OM) de Ensino, que aplicavam a metodologia, sistematicamente.

Para o presente estudo de caso, a documentação analisada incluiu o capítulo onze da DGPM-101, 3a revisão (MARINHA DO BRASIL, 2000), e seus anexos que tratam da metodologia anterior, o Manual de Avaliação do Sistema de Ensino Naval (MARINHA DO BRASIL, 2005b) - DEnsM-2001 (Diretoria de Ensino da Marinha), que apresenta a metodologia de avaliação a ser empregada nas Organizações Militares (OM) do Sistema de Ensino Naval (SEN), bem como o capítulo três da DGPM-101, 4ª revisão (MARINHA DO BRASIL, 2005c), que normatiza a nova metodologia. Além da análise documental, foram realizadas entrevistas com três pedagogas, uma das quais responsável pela elaboração da nova metodologia de avaliação do SEN, e as outras duas responsáveis pela sua aplicação nas suas OM (ENEscola Naval e CIAW- Centro de Instrução Almirante Wandenkolk). Por motivos relativos à ética da pesquisa, os nomes das en- trevistadas foram mantidos no anonimato. As entrevistas serviram para esclarecer detaIhes considerados relevantes para a análise da metodologia de avaliação proposta e contribuir para o alcance dos objetivos traçados para o estudo.

A partir das considerações anteriores, dois eixos nortearam a análise realizada sobre a avaliação institucional do Sistema de Ensino Naval. Em um primeiro, tratavase de ver as hibridizações entre discursos políticos que permeiam a concepção de avaliação. Em uma perspectiva multicultural, que busca superar dicotomizações apriorísticas, detectamos, nesse eixo, discursos escritos e falados que se reportavam à convivência e às ressignificações híbridas entre influências do SINAES, por um lado, e de políticas voltadas à qualidade total na educação, por outro, dentro da perspectiva de avaliação institucional na Marinha. Em um segundo eixo, verificamos as tensões entre o pólo de regulação e o de valorização da diversidade cultural na Marinha. Intimamente relacionado a este eixo, encontra-se a necessidade apontada por Canen e Canen (CANEN, A.; CANEN, A. G., 2005; CANEN, A. G.; CANEN, A. 2005), de respeito à identidade institucional das organizações multiculturais. No caso em pauta, trata-se da Marinha, como organização própria, com cláusulas pétreas e missão cultural singular que, no contexto de um processo de avaliação institucional a partir do olhar multicultural que defendemos, deve ser respeitado e incorporado, ainda que sempre tensionado com a pluralidade cultural dos atores e das próprias instituições de ensino que compõem o Sistema de Ensino Naval. Nesse sentido, procurou-se detectar, a partir da documentação e das falas dos atores, possíveis ca- 
minhos pelos quais o dinâmico equilíbrio entre as tensões avaliativas pudesse ser aprimorado, de modo a incentivar a negociação entre os mesmos.

No primeiro eixo de análise, verificamos que a avaliação institucional do SEN defende a idéia de processo, de busca de um contínuo aperfeiçoamento, em uma perspectiva diagnóstica, como evidenciado no extrato a seguir: "A avaliação institucional no SEN constitui-se em processo de contínuo aperfeiçoamento do desempenho acadêmico e do planejamento da gestão da instituição" (MARINHA DO BRASIL, 2005b).

Quando a avaliação é definida como um processo permanente de aprimoramento, o documento esclarece que seus resultados devem ser discutidos e analisados, não deixando margem para que o processo avaliativo se encerre nos relatórios, em uma perspectiva meramente contemplativa. Este aspecto se assemelha ao princípio da continuidade do processo avaliativo, defendido pelo SINAES (2004) e corroborado por autores como Dias Sobrinho (2004) e Ristoff (1996). Após o processo de avaliação da $O M$ de Ensino, faz-se a divulgação dos resultados e estes devem ser discutidos e analisados por diferentes segmentos, conforme se verifica no trecho a seguir:

Ao processo de avaliação deve seguirse um trabalho bem planejado de difusão de resultados e de suas análises, permitindo que ela seja discutida por diferentes segmentos e seus resultados examinados em função da diversidade de características dos estabelecimentos de ensino que compõem o SEN (MARINHA DO BRASIL, 2005b).

Verificamos na sentença acima, uma semelhança com o princípio do reconhecimento da diversidade, proposto pelo SINAES e nomeado por Ristoff (1996) como respeito à identidade institucional, ao defender que os resultados coletados serão examinados em função da diversidade de características dos estabelecimentos de ensino que compõem o SEN. Também encontramos semelhança com o princípio da flexibilidade, proposto pelo SINAES, que sugere um equilíbrio entre as avaliações para a regulação e para a diversidade, utilizando tanto critérios objetivistas, quanto relativistas. Estes aspectos podem ser considerados como um avanço nas práticas avaliativas da Marinha, pois, como podemos perceber, ambas procuram a mediação entre os enfoques avaliativos, buscando trabalhar as tensões entre diversidade e regulação na avaliação (CANEN, 2005).

No trecho "é necessário criar, em todos os níveis, a consciência de que a avaliação é uma necessidade para qualquer esforço de melhoria" (MARINHA DO BRASIL, 2005b), destacamos a idéia de criação da consciência da avaliação nas Organizações de Ensino. Essa consciência é denominada por Ristoff (1996) de cultura da avaliação, que se faz necessária para que todos os envolvidos com o ensino e a com a instituição reconheçam a importância da avaliação para seu crescimento pessoal e institucional. A Diretoria de Ensino da Marinha (DEnsM) pretende, ao capacitar tecnicamente avaliadores, modificar a visão negativa que alguns têm da avaliação, relacionando-a a sentimentos de punição e fracasso. Diminuir as resistências em relação à avaliação, para que o avaliado não se sinta inibido e/ou constrangido, certamente tornase passo importante para o sucesso de uma avaliação que pretende ser "um processo 
investigativo e participativo, fundamentado no diálogo, possuindo função diagnóstisca, formativa e classificatória" (MARINHA DO BRASIL, 2005b). Dessa forma, a avaliação que a Marinha propõe possui funções diagnósticas, formativas e classificatórias, sem propor separações, compreendendo procedimentos quantitativos e qualitativos.

No mesmo sentido, a avaliação incorpora o princípio da globalidade do processo avaliativo, defendido no SINAES (2004), contemplando cinco dimensões: Corpo Docente, Corpo Discente, Organização Didático-Pedagógica, Instalações e Avaliação Pós-Escolar, com diferentes categorias de análise. Essas dimensões, quando trabalhadas a partir dos resultados da avaliação, propiciam uma conseqüente melhoria na última dimensão, a Pós-Escolar. $\bigcirc$ programa de avaliação propõe-se a ser abrangente e eficaz, na medida em que promove a integração vertical e horizontal dos seus cursos. Essa preocupação com a abrangência da avaliação pode ser considerada um avanço em relação à metodologia anterior, até porque ela exige o envolvimento de todos os elementos da OM, tanto dos que oferecem o curso avaliado, quanto dos que oferecem o apoio necessário para que ele aconteça, como também o envolvimento daqueles que recebem os militares formados pelo curso e realizam a Avaliação Pós-Escolar.

Entretanto, ao mesmo tempo em que a influência do SINAES (2004) se faz perceber, o impacto da visão de qualidade total hibridiza-se no discurso da avaliação institucional em pauta. Assim, desde 1992, a Marinha vem incentivando os comandantes/diretores a aplicarem uma forma de gestão em suas unidades, voltada à qualidade e à produtividade. Adotou-se a Gestão pela Qualidade Total (GQT), que veio a ser substituída pela Gestão Contemporânea (GECON). De fato, em 1998, foi publicada a doutrina da gestão contemporânea, que sofreu sua primeira revisão em 2002, passando a denominar-se Manual de Gestão Contemporânea da Marinha (EMA-131). O propósito do documento é servir de ferramenta para auxiliar os titulares de OM na administração de suas unidades, como se verifica abaixo:

A Marinha identifica, no modelo da GECON, conceitos, princípios e métodos que, corretamente adaptados à sua realidade, serão úteis ao desempenho das tarefas que lhe são atribuídas. São reconhecidas, igualmente, as diferentes características das diversas OM que a compõem, de forma que cada uma delas deve buscar, no extenso campo da GECON, os instrumentos que the sejam adequados. Todos os segmentos têm um vasto campo para explorar e aplicar modernas práticas administrativas, técnicas e metodologias, consolidadas na forma da GECON [...] (MARINHA DO BRASIL, 2002, p. 1-3).

Em função do exposto, não é de se estranhar que, nos documentos que regulam o ensino na Marinha, também se encontrem palavras que compõem o linguajar da gestão administrativa. A nova metodologia de avaliação do SEN adota os princípios da GECON como fundamentos do método, a saber: a satisfação do usuário, a liderança participativa, o gerenciamento de processos, a valorização das pessoas, a constância de propósitos, a melhoria contínua, a não-perpetuação de erros, a delegação, a disseminação de informações e a 
garantia de qualidade.

A hibridização discursiva entre uma perspectiva de avaliação voltada a princípios da qualidade total e aquela preconizada pelo SINAES (2004) evidencia uma tensão, que caracteriza o primeiro eixo ora em análise da avaliação empreendida.

O segundo eixo da análise, por sua vez, detecta a hibridização discursiva entre o controle e a regulação da avaliação proposta, por um lado, e a tentativa de dar conta da diversidade cultural presente nas organizações do Sistema de Ensino Naval. $\bigcirc$ respeito à diversidade é reforçado no capítulo que define os indicadores da qualidade do ensino, quando se estabelece que cada indicador, "em função de suas características próprias e das especificidades dos diferentes estabelecimentos de ensino, poderá ser composto de vários aspectos e, conseqüentemente, aferido por mais de um índice". (MARINHA DO BRASIL, 2005b). Assim como no SINAES (2004), a metodologia de avaliação da Marinha permite que sejam propostos procedimentos adaptáveis às diferentes estruturas. $\bigcirc$ instrumento avaliativo da $\mathrm{OM}$ foi elaborado pela DEnsM, seguindo sugestões da própria OM, que pôde propor alterações visando a adequar o modelo à sua realidade. De fato, ao perguntarmos se houve momentos de discussão de sugestões de melhoria para nova metodologia e sobre quem participou de sua construção, as respostas foram as seguintes:

A discussão para a nova metodologia já começou durante os momentos de aplicação do SAVSEN [Sistemática de Avaliação do Sistema de Ensino Naval]. Porque já eram sentidas algumas dificuldades, sendo que alguns dados, jul- gados necessários, não apareciam como resultado daquela sistemática.[...] Mas nós fomos, ao longo dos anos, acumulando sugestões, algumas já tinham sido atendidas e outras não. $A$ partir dessas colocações, muitas necessidades foram apresentadas pelos Comandantes das OM. Nós passamos a propor, com base num trabalho já realizado por uma das OM, no caso a Escola Naval, às $\mathrm{OM}$ que iriam participar da sistemática, que analisassem a proposta e que nos fornecessem sugestões para que nós pudéssemos fazer um trabalho voltado para as características específicas de cada $O M$, sem perder uma idéia de que nós teríamos que trabalhar com dimensões que seriam semelhantes para todas as $O M$ de Ensino, independentes do nível de ensino ministrado [...] Então, embora eu tenha dimensões semelhantes, vou, dentro dessas dimensões, adequar ao nível de ensino em que eu estou trabalhando. (Pedagoga A, 2005). [...] todas as $\mathrm{OM}$ de Ensino, que compõem o SEN, deram a sua contribuição [...] todas as $\mathrm{OM}$ receberam o material, fizeram uma análise e deram contribuições para adequar aquele modelo à realidade da sua OM. Com base nisso, nós procuramos trocar, na medida do possível, o máximo de vezes, usando os recursos da informática para isso, e fizemos esse primeiro Manual, esse primeiro modelo, para que seja testado praticamente na primeira aplicação no ano em curso. (Pedagoga A, 2005, grifo nosso).

É uma avaliação institucional. Tenta pegar todos os aspectos mais importantes, essas dimensões envolvidas são as mais importantes. E a avaliação está toda nesse sentido mesmo, em volta dessas 
perguntas todas, com relação à análise dos resultados. Há um objetivo de feedback muito importante [...] E essa parte agora está bem fechada nessa metodologia, que é a análise do material. (Pedagoga B, 2005).

Uma coisa muito importante é essa visão geral da educação, do ensino e não somente a parte de instrutor, somente no desempenho em sala de aula [...] A parte de currículo, a parte didática mesmo do instrutor e outras categorias que envolvem aspectos de avaliação, que indiretamente fazem parte do processo. É uma metodologia ampla, que tem contemplado diversas dimensões, pois antes, a gente ficava mais restrita à sala de aula mesmo. (Pedagoga C, 2005).

[...] Nós estamos conhecendo essa metodologia agora, com essas partes todas, essas fases, que estão sendo feitas, com a avaliação interna e a avaliação externa, em duas etapas. Então, isso é tudo novo para nós. $\bigcirc$ que veio, já baseado nessa DEnsM-2001, foi um primeiro questionário, para nós propormos sugestões de alteração das questões e analisar se as questões eram cabíveis à nossa realidade, às nossas necessidades [...] Depois do envio dessas sugestões é que foi montado um roteiro de avaliação, que é o RotA,mais específico [...]. (Pedagoga C, 2005).

A tentativa de articulação do modelo geral à diversidade cultural na Marinha, observada nos depoimentos acima que indicam esforços de discussão de indicadores gerais e aqueles mais coadunados com a realidade de cada uma das OM, também esteve presente nos apêndices e adendos do manual, que apresentam, por exemplo, roteiros diversificados para a avalia- ção da dimensão pós-escolar, contemplando as especificidades dos diferentes estabelecimentos de ensino. Os roteiros para avaliação pós-escolar possuem aspectos gerais a serem observados e avaliados nos desempenhos dos alunos formados, que são comuns a todas as $O M$, mas, também, trazem um espaço em branco a ser preenchido por elas em relação aos aspectos específicos, que deverão ser incluídos por curso, em função do perfil do egresso. Observamos que o número de índices a ser considerado variará de acordo com as características do curso que está sendo avaliado. Esses índices foram construídos pela DEnsM em parceria com as OM de Ensino e, algumas delas, como a Escola Naval, enviaram sugestões de alteração para adequá-los às suas realidades.

Após a análise comparativa dos RAlnt. (Relatórios de Avaliação Interna), constatamos que a Dimensão Pós-Escolar foi a que mais procurou se adequar às diferentes realidades, contemplando as especificidades das distintas Organizações de Ensino, pois, além de os roteiros apresentarem aspectos adequados aos diversos tipos e níveis de ensino, as avaliações feitas em relação aos desempenhos dos ex-alunos são específicas para cada curso, seguindo uma relação de aspectos elaborada de acordo com as disciplinas do currículo e as Relações de Tarefas Técnico-Profissionais (RTTP) dos mesmos. Nesses roteiros constam também espaços para o preenchimento dos pontos positivos e dos pontos que precisam ser melhorados no curso, assim como apontam conteúdos que necessitam de reforço ou que deixaram de ser abordados no curso avaliado. Apresentam, também, um campo para que os avaliadores, ex-aluno e o Comandante/Chefe imediato 
da $\mathrm{OM}$ em que serve o ex-aluno, possam apresentar as observações e sugestões que julgarem pertinentes e necessárias à meIhoria da formação oferecida.

Pensar multiculturalmente, como temos argumentado, também parte da valorização da identidade cultural da instituição, por intermédio de sua especificidade, sua missão, entendendo-a como organização multicultural, que trabalha a tensão entre a diversidade e a construção de sua própria identidade (CANEN, A. G.; CANEN, A., 2005; CANEN, A.; CANEN, A. G., 2005). No caso em pauta, tal tensão perpassa o processo avaliativo, como, por exemplo, quando se percebe que os currículos dos cursos devem estar adequados ao perfil que a Marinha deseja para seus militares. A Diretoria de Ensino da Marinha elaborou, recentemente, a publicação DEnsM- 1001 com uma coletânea das Relações de Tarefas Técnico-Profissionais que os militares devem cumprir após formados nos diversos cursos que a Marinha ministra. Estas tarefas servem de parâmetros para que a avaliação pós-escolar seja realizada pelos Chefes diretos/ Comandantes das $O M$ em que vão servir estes militares. Os resultados da avaliação pósescolar, portanto, vão servir para avaliar a qualidade dos cursos oferecidos pelas diversas $\mathrm{OM}$ de Ensino e da adequação dos perfis dos militares nos seus distintos corpos, quadros e especialidades. Fica evidenciada a especificidade cultural desta instituição, que possui, inclusive, legislação própria para regular o seu ensino, a Lei $n^{\circ}$. 11.279, de 9 de fevereiro de 2006. Nesse caso, a avaliação institucional está estreitamente ligada ao projeto e à identidade institucional, que, no caso da Marinha, está definida institucionalmente, conforme disposto em lei, que afirma que o ensino da Marinha destina-se a
"[...] capacitar o pessoal militar e civil para o desempenho, na paz e na guerra, dos cargos e funções previstos em sua organização [...]." (MARINHA DO BRASIL, 2006).

De fato, na Marinha, o ensino oferecido é de caráter técnico-profissional e deve garantir o preparo do militar para realizar as tarefas relativas à sua formação. Cada especialização requer o cumprimento de tarefas específicas, explicitadas na publicação DEnsM-1001. Para dar conta do respeito à identidade cultural da Marinha, as competências indispensáveis na formação do militar, após realização do curso, passam a estar incluídas nos currículos dos cursos. $\bigcirc$ "perfil" desejado para Oficiais e para Praças deve ser previamente definido para que, após essa definição, sejam organizados os conteúdos a serem ministrados nos cursos. Podemos afirmar que, para a Marinha, o ensino oferecido nos cursos é de qualidade quando prepara adequadamente o militar para que ele tenha atitudes e habilidades necessárias para desempenhar as funções exigidas nas diversas $O M$, contribuindo para o cumprimento de suas missões. Portanto, o ensino deve ter qualidade formal e atender às especificidades da Organização Militar. A tensão entre o respeito à diversidade cultural presente nas organizações que compõem o Sistema de Ensino Naval e a necessidade de balizar a avaliação com a identidade cultural da Marinha emerge, com clareza, no depoimento abaixo:

A abrangência, talvez, tenha sido a maior mudança, porque quando se falava em avaliação de Corpo Docente, por exemplo, ele estava sendo avaliado com base em roteiros e, basicamente, era $\mathrm{o}$ seu desempenho didático que era pontuado [...] Hoje não [...], a gente também 
tem que ter o resultado do aspecto de formação militar e não só do aspecto acadêmico. Então, tem que ver em termos de disciplina, como está o militar que eu estou formando. Eu quero o profissional, mas o profissional que eu estou querendo é o militar, então este aspecto também passa a ser contemplado. Uma outra diferença também muito significativa é que nós procuramos ouvir as OM para poder construir instrumentos diferenciados para cada OM. Assim, ainda que eu tenha todas as dimensões, os aspectos considerados não precisam ser exatamente os mesmos para todas as $\mathrm{OM}$ e os percentuais também. Por exemplo, eu não posso ter uma exigência de titulação semelhante numa Escola $\mathrm{Na}$ val, que é uma instituição de ensino de nível superior, e para uma Escola de Aprendizes [...] (Pedagoga A, 2005).

Como se observa, a identidade institucional cultural da Marinha não pode ser desconsiderada ou analisada fora de seu contexto. Uma análise multicultural que apenas privilegiasse uma perspectiva relativista de avaliação deixaria, talvez, de captar a especificidade cultural da identidade organizacional em pauta e da necessidade de relacionar critérios objetivistas para a sua avaliação com aqueles mais diferenciados por organização. Como observado anteriormente, o respeito à identidade institucional cultural tem sido apontado como objeto do multiculturalismo, que preconiza a valorização da pluralidade de identidades, inclusive institucionais (CANEN, A. G.; CANEN, A., 2005; CANEN, A.; CANEN, A. G., 2005).

Por outro lado, no entanto, trata-se, a partir da perspectiva avaliativa que defen- demos, de analisar em que medida ênfases em um dos pólos acima citados podem comprometer o equilíbrio dinâmico entre os mesmos. Observa-se que esse perigo existe, na medida em que o pólo da diversidade e da negociação passarem a ser tensionados com a ênfase na construção e respeito à identidade institucional da Marinha, como organização própria, em que uma exacerbação do pólo da homogeneização e da regulação possam vir a ocorrer. A partir do referencial e do argumento abraçados, ainda que o perfil pertinente à identidade cultural e institucional seja necessário e faça parte do pólo da regulação na avaliação institucional da Marinha, verificar em que medida uma ênfase em tal pólo possa estar comprometendo o equilíbrio com a negociação e o respeito à diversidade cultural pode permitir ajustes e aprimoramentos no processo avaliativo. Nesse sentido, a metaavaliação, segundo Penna Firme (1994), torna-se, etapa fundamental no processo avaliativo, considerando-se sua utilidade, viabilidade, exatidão e ética, bem como, a partir de nossa argumentação, o equilíbrio entre a regulação e a valorização do plural em seu bojo. É importante salientar que a metodologia ora em análise ainda está em seus primórdios, com potenciais para ajustes na perspectiva que defendemos.

Por outro lado, sobre a possibilidade de a Marinha, como uma instituição militar, trabalhar a dimensão política e multicultural da avaliação, foi possível verificar que a Diretoria de Ensino tem incentivado a participação de todos os envolvidos no processo avaliativo, sugerindo mudanças e buscando o constante aperfeiçoamento da metodologia. Para a dimensão política e multicultural, faz-se necessária a reflexão crítica de todos os envolvidos e seu com- 
promisso com o crescimento da instituição ou estabelecimento de ensino, através da discussão e construção coletiva de soluções e de negociação, o que pode ser ilustrado nos seguintes depoimentos:

A qualidade do ensino ainda não foi atacada pela metodologia, porque os resultados ainda não se fizeram chegar. Ela já tem criado um burburinho nas bases internas. Por causa da cobrança do Relatório de Avaliação Interna, de algumas perguntas, de algumas questões, é que as pessoas têm que começar a se mexer [...]. Mas os reflexos no ensino, na parte de qualidade do ensino, são mais lentos, e no transcorrer do ano, você não vai sentir isso. Infelizmente, a metodologia, como qualquer uma delas, na minha opinião, tem esse porém, de não oferecer os resultados de imediato, de não alterar uma qualidade da noite para o dia, ela ainda está mexendo nas bases. (Pedagoga B, 2005).

Eu acho que um ganho que a gente teve foi a gente se desvincular da IAM no processo de avaliação do ensino. [...] As pessoas começaram a se envolver mais [...] a gente fala da avaliação, desta vez relacionada à DEnsM-2001, ao manual, que é a nossa IAM [Inspeção Administrativo-Militar], uma IAM particular, eu diria assim, porque as pessoas já se mobilizam mais para isso [...] A gente tem um tempo maior dedicado mais para essa parte do ensino e, se realmente a gente tiver um retorno, com pessoas que têm - eu não diria responsabilidade, mas um real comprometimento nessa parte da educação - [...] acho que a gente vai ter um ganho muito grande com essa nova metodologia. (Pedagoga C, 2005).

A idéia que tem sido colocada com bas- tante ênfase é a questão de que a avaliação não morra a partir do momento que eu obtiver um conceito [...] eu tenho que observar os dados que eu coloquei, os procedimentos adotados, se eles surtiram o efeito desejado, fazer um acompanhamento desse trabalho. Eu não vou começar sempre do zero e ficar batendo palmas para o resultado sem comparar [...] eu posso ter algumas situações que eu tenha que analisar, considerando todos os aspectos e não apenas um número frio [...] (Pedagoga A, 2005).

Longe de serem trabalhados de forma estanque, os eixos de análise no estudo de caso em pauta imbricam-se e compõem o complexo cenário da avaliação institucional. Os desafios a serem enfrentados de modo a caminhar na direção do equilíbrio entre a regulação e a diversidade cultural, entre perspectivas de gerenciamento e aquelas de valorização da instituição em sua dimensão educacional, bem como entre o respeito à identidade institucional e a pluralidade cultural das instituições e dos atores aí presentes certamente podem contribuir para o avanço da avaliação rumo à complexa construção e reconstrução de sua identidade, em um mundo cada vez mais complexo e plural.

\section{Conclusões}

presente estudo partiu da visão dos paradigmas e políticas avaliativas como imbuídos de tensões inerentes ao processo de avaliação, enriquecidas pela construção de conhecimento na área e pela análise das políticas públicas de avaliação do ensino superior que têm encontrado espaço crescente no Brasil, a partir principalmente dos anos 90. Argumentamos que o multiculturalismo pode trazer contribuições para a área, buscando trabalhar tensões entre o 
respeito às identidades institucionais e a incorporação da diversidade cultural aí presente, bem como entre perspectivas de regulação e controle com outras de negociação e respeito à pluralidade cultural.

Da mesma forma, partindo de uma visão sobre o SINAES no sentido de perceber seus avanços no trabalho com as tensões acima citadas, o estudo de caso da avaliação institucional recentemente implantada no Sistema de Ensino Naval evidenciou que, ao mesmo tempo em que se discute a necessidade de critérios de qualidade exigidos para uma $\bigcirc M$ de Ensino eficiente, tais critérios são muitas vezes ressignificados, negociados e hibridizados, dentro de visões plurais presentes nas instituições. Tal estudo permite visualizar tensões e potenciais do multiculturalismo para o aprimoramento da avaliação institucional em perspectivas que buscam superar dicotomias e dogmatismos e resgatar hibridizações de discursos avaliativos e possibilida- des para caminhar no sentido de equilíbrios entre pólos em tensão, no processo de avaliação. Da mesma forma, permite que possamos estar atentos à necessária articulação entre o respeito à identidade institucional das organizações e a diversidade cultural aí presente. Olhar multiculturalmente para essas tensões evita dogmatizações e permite que se verifiquem limites, problemas a serem corrigidos, assim como espaços possíveis de avanço do processo avaliativo, para o crescimento institucional.

Ao questionar a construção das diferenças e dos preconceitos, bem como ao denunciar o congelamento identitário e as dicotomias e dogmatizações discursivas, o multiculturalismo como olhar teórico sobre a avaliação institucional, permite perceber hibridizações, movimentos, possibilidades e contradições na tradução de intenções em ações, rumo ao aprimoramento constante da avaliação institucional.

\section{Referências}

BRASIL. Lei n . 10.861, de 14 de abril de 2004. Institui o Sistema Nacional de Avaliação da Educação Superior - SINAES, e dá outras providências. Legislação, Brasília, DF, 2004. Disponível em: http://www.inep.gov.br/download/superior/2004/Legislacao/ LEI_n10861_14_4_04_SINAES.doc. Acesso em: 16 abr. 2007.

BRASIL. Lei $n^{\circ} .11 .279$, de 9 de fevereiro de 2006. Dispõe sobre o ensino na Marinha. Casa Civil, Brasília, DF, 2006. Disponível em: < https://www.planalto.gov.br/ccivil/ Ato2004-2006/2006/Lei/L1 1279.htm >. Acesso em: 17 abr. 2007.

CANEN, A. G.; CANEN, A. Organizações multiculturais: logística na corporação globalizada. Rio de Janeiro: Ciência Moderna, 2005.

CANEN, A. Avaliando a avaliação a partir de uma perspectiva multicultural. Educação Brasileira: revista do CRUB, Brasília, DF, v. 27, n. 54, p. 95-114, 2005.

Institutional evaluation, knowledge and multiculturalism: some ways ahead in Brazilian Higher Education. Current Issues in Comparative Education, v. 6, n. 1, 2004. Disponível em: <http://www.tc.columbia.edu/cice/articles/acl61.htm>. Acesso em: 
CANEN, A.; CANEN, A. G. Rompendo fronteiras curriculares: o multiculturalismo na educação e outros campos do saber. Currículos sem Fronteiras, [S. I.], v. 5, p. 40-49, jul./dez. 2005.

DIAS SOBRINHO, J. Sobre a proposta do Sistema Nacional de Avaliação da Educação Superior (SINAES). Avaliação: revista da Rede de Avaliação Institucional da Educação Superior, Campinas, SP, v. 9, n. 1, p. 113-124, 2004.

GUBA, E.; LINCOLN, Y. Uma abordagem naturalista para a avaliação: o amadurecimento da avaliação. In: SANDERS, J. (Org). Introdução à avaliação de programas sociais: coletânea de textos. São Paulo: Instituto Fonte para o Desenvolvimento Social, 2003.

INEP. Sistema Nacional de Avaliação da Educação Superior: da concepção à regulamentação. 2. ed. ampl. Brasília, DF, 2004.

MARINHA DO BRASIL. Diretoria de Ensino da Marinha. DEnsM-1001. Coletânea das relações de tarefas técnico-profissionais do Corpo de Praças da Armada e do Corpo Auxiliar de Praças. Rio de Janeiro, 2005a.

MARINHA DO BRASIL. Diretoria de Ensino da Marinha. DEnsM-2001. Manual de Avaliação do Sistema de Ensino Naval. Rio de Janeiro, 2005b.

MARINHA DO BRASIL. Diretoria-Geral do Pessoal da Marinha. DGPM-101 ( $3^{a}$ revisão). Normas para os cursos e estágios do Sistema de Ensino Naval (SEN). Rio de Janeiro, 2000 .

. Diretoria-Geral do Pessoal da Marinha. DGPM-101 (4a revisão). Normas para os cursos e estágios do Sistema de Ensino Naval (SEN). Rio de Janeiro, 2005c.

. Estado-Maior da Armada. EMA-131 ( ${ }^{a}$ revisão). Manual de gestão contemporânea da MB. Rio de Janeiro, 2002.

PENNA FIRME, T. Avaliação: tendências e tendenciosidades. Ensaio: avaliação de políticas públicas em avaliação: revista da Fundação Cesgranrio, Rio de Janeiro, v. 1, n. 2, p. 5-12, 1994.

RISTOFF, D. I. Princípios do Programa de Avaliação Institucional. Avaliação: revista da Rede de Avaliação Institucional da Educação Superior, Campinas, SP, n. 1 , v. 1, p. 47-53, 1996.

Recebido em: 30/1 1/2006

Aceito para publicação em: 11/04/2007 